SYMPOSIUM ON CIRCUMCISION

\title{
Rationalising circumcision: from tradition to fashion, from public health to individual freedom - critical notes on cultural persistence of the practice of genital mutilation
}

\author{
S K Hellsten
}

J Med Ethics 2004;30:248-253. doi: 10.1136/jme.2004.008888

Correspondence to: S K Hellsten, Centre for the Study of Global Ethics, University of Birmingham ; s.k.hellsten@bham.ac.uk; cc skhellsten@yahoo.co

Received 24 March 2004 Revised version received 25 March 2004

Accepted for publication 25 March 2004
Despite global and local attempts to end genital mutilation, in their various forms, whether of males or females, the practice has persisted throughout human history in most parts of the world. Various medical, scientific, hygienic, aesthetic, religious, and cultural reasons have been used to justify it. In this symposium on circumcision, against the background of the other articles by Hutson, Short, and Viens, the practice is set by the author within a wider, global context by discussing a range of rationalisations used to support different types of genital mutilation throughout time and across the globe. It is argued that in most cases the rationalisations invented to provide support for continuing the practice of genital mutilation-whether male or female-within various cultural and religious settings have very little to do with finding a critical and reflective moral justification for these practices. In order to question the ethical acceptability of the practice in its non-therapeutic forms, we need to focus on child rights protection.
D espite global and local attempts to end genital mutilations, in their various forms, whether of males or females, the practice has persisted throughout human history in most parts of the world. Today both male and female genital mutilation are particularly common in poor, developing countries with wide traditional communities, but these practices have also been maintained in many modern Western multicultural societies. This is particularly the case with male circumcision, which in many parts of the Western world is still practised almost routinely, as the articles by Hutson, Short, and Viens on the justification of male circumcision in this journal, show. ${ }^{123}$

Short and Hutson focus more on scientific, medical, and public health aspects while Viens discusses the issue of religious freedom and identity. More precisely, Hutson analyses whether the public health argument holds water in justifying male circumcision as a routine operation in relation to its health related consequences (whether these are negative or positive). Short's commentary on Hutson defends male circumcision on the basis of medical evidence that the procedure (on males) has been scientifically proven to improve both male and female reproductive health. Short goes as far as suggesting that we might have some kind of duty to develop better procedures to make the operation the "kindest cut of all". Viens, on the other hand, argues for the justification of male circumcision on the basis of individual freedom. Rather than speaking for the right of an individual to make his or her own autonomous choices, however, Viens draws his arguments from the parents' right to decide what is best for their children as well as from the parents' religious freedom to choose the (religious) identity of, and for, their children. While Hutson is the most hesitant of these three authors to defend the general benefits of the operation, none of these articles directly argues against male genital mutilation. While Viens is most sensitive to religious freedom and cultural identity, none of the authors discuss in detail the different cultural, social, and economic contexts of these values and practices across the globe. Instead, all the above mentioned authors keep their discussion almost exclusively within the framework of Western medicine and a pluralist society. While, albeit briefly, supporting other cultures' rights to maintain their religious identities, Viens is even willing to offer Western assistance in developing less painful and medically safer practices for the operation on children elsewhere in the world. In this symposium, and against the background of the articles by these three authors, I have taken it as my task to set this discussion on the justification of male circumcision within a wider, global context. I want to discuss how we find a range of rationalisations to support various types of genital mutilation and to evaluate whether these rationalisations have anything to do with a critical and reflective moral justification of these practices.

I shall pay attention to the following issues. Firstly, I find it disturbing that even within the Western medical community, there is evidently still a wide consensus on such an intrusive and violent procedure as male circumcision, albeit that this consensus is evidently based on very different "moral" justifications, which vary from public health, to scientific proof, to religion and to a diversity of Western values. More worrying is the fact that there appears to be a general agreement that this violent procedure (as therapeutic and non-therapeutic one) can (and according to Viens, even should) be carried out on infants and/or very small children. In addition, male genital mutilation (MGM) should not be considered in isolation from the issue of female genital mutilation (FGM). In this symposium only Viens recognises the existence of "female genital cutting". He, however, regards it as part of the same tradition which encourages MGM - that is, a tradition based on religious freedom/ cultural identity - without making any attempt to distinguish the different nature of the medical and moral reasons put forward in favour of FGM.

Secondly, I find that both the medical and the value based arguments presented by these three authors lack either plausible evidence or logical consistency. Instead of discussing each article separately, however, I shall describe a wider global framework that provides false reasons in defence of genital mutilation, rather than providing any truly plausible moral justification for this practice. 


\section{RELIGIOUS FREEDOM, PAIN, AND CHILDREN'S RIGHTS}

Throughout history human beings have mutilated and harmed their bodies (and minds) in the name of culture, tradition, religion, and concepts of beauty, health, normality, or social status. One of the most persistent forms of these physical violations is mutilation of human genitalia. This practice has been related to: taboos about human sexuality; children's initiation to adulthood, maturity, and reproductive age; aesthetic values; the demands set by various religions, and to hygienic, individual, and public health medical beliefs. (See the articles by Hutson, Short and Viens in this journal, and also those by Aldeeb Abu-Salieh, Bigelow, and by an anonymous author in Echo). ${ }^{1-7}$ All in all, mutilation of human sexual organs reflects our fears about human biological needs - and even deeper fears about human sexual needs-as well as fears to do with the maintenance of established social hierarchies in a society.

In this symposium we are discussing the most common form of genital mutilation, male circumcision. In its mildest form, this means the cutting of the foreskin of the penis. (For more detailed explanations see the articles by Hutson, Short, and Viens). ${ }^{123}$ It is important to note, however, that the same term, "circumcision" is also used in relation to women's genital mutilation, where it refers to the cutting of the tip or the whole of the clitoris. There are, however, various other, more radical and more harmful mutilations of human genitalia, which can be relatively minor or extremely serious. Female genital mutilation-for example, includes a wide range of ritual and non-medical operations undertaken on women's genital organs, which include their total or partial removal and amputation or incisions in the interior of the vagina. According to the World Health Organisation (WHO) female genital mutilation can be classified into three major types: type I or clitoridectomy-removal of the tip of the clitoris; type II-cutting of the clitoris and all or part of the labia minora, and type III or infibulation or pharaonic circumcision, in which the clitoris is cut together with part or the whole of the labia minora and incisions are made on the labia majora. When this latter operation is performed, the edges of the wound are often tied up again leaving a small opening through which body liquids such as urine or menstrual blood can flow. The resulting mass of scar tissue which covers the urethra and the upper part of the vagina, completely closes the vulva. If the opening is wide enough, sexual intercourse may occur after a gradual dilatation, which can take days, weeks or even months. When the opening is too small to allow sexual intercourse, it must be widened with a razor or knife on the wedding night. Given the severity of cuts and stitches occurring during initial and repeated interventions, infibulation is the most harmful form of genital mutilation, both to reproductive health and to health in general. Other practices which prevail in certain countries of Central, Southern, and South Africa, consist in pulling the labia and introducing substances and minerals into the vagina to dry it and to increase men's sexual pleasure (Anonymous, ${ }^{6}$ p 5). Male genital mutilation can vary from body piercing through a range of various other modifications to amputation, and castration.

While the moral justification for any type of genital mutilation has been challenged from time to time, its continuation for both men and women has been rationalised over and over again via various medical, legal, moral, and cultural arguments. The campaigns against MGM have not been as vigorous as those against FGM since FGM is in general considered to be a more violent and socially suppressive practice than MGM. In addition FGM has more serious and damaging physical, as well as psychological or social, implications. On the other hand, the operation itself has no medical justification, whereas a medical justification is still put forward for MGM, as the articles by Hutson, Short, and Viens show. Thus, male circumcision has been easier to accept as a minor harm that can be justified, or at least tolerated, if not sometimes encouraged (see Short's paper in this journal) as a part of a particular religious or cultural tradition or as a measure promoting individual or public health.

In general, the arguments against MGM or FGM claim that both practices violate the physical integrity of children and cause avoidable pain. In the worst cases they can lead to irreversible physical or psychological harm, as noted by Huston in his contribution to this symposium. It appears, however, that while neither, Hutson, Viens, nor Short recommend male circumcision as a public health measure, in individual cases they all accept male circumcision either on medical or on religious grounds, as long as it does not cause pain. Thus, they recommend better pain management measures and more refined procedures to perform the operation. This is particularly true of Viens's argument, which defends, the practice in the name of religious freedom but denies the fact that the operation is-or should bepainful. This position appears to be contradictory, since as a religious or cultural practice, the endurance of pain is often an essential part of the ritual, showing the readiness of individuals to transit from childhood to adulthood, from boy to man, in the case of MGM, and from girl to woman in the case of FGM. The other problem with Viens's argument for religious freedom in relation to male circumcision is that it supports male circumcision being carried out on infants and small children at the request of their parents, rather than waiting for the children to be "old" enough to give their "informed consent" and to understand the real significance of the ritual and "the need to tolerate pain".

From a human rights perspective both male and female genital mutilation, particularly when performed on infants or defenceless small children, and for non-therapeutic reasons can be clearly condemned as a violation of children's rights whether or not they cause direct pain. Parents' rights cannot override children's rights. If we allow parents to decide what is best for their children on the basis of the children's religious or cultural identity, we would have no justification for stopping them cutting off their children's ears, fingers, or noses if their religious and cultural beliefs demanded this. Also, if we allow parents' rights to override children's rights, we could not then forbid them from making any other physical and spiritual sacrifices, (such as "cannibalism" or "human sacrifice" as extreme examples), particularly if we follow Viens's recommendation and manage to develop techniques that minimise or abolish pain.

TRADITION OF GENITAL MUTILATION AND GENDER This article focuses on male circumcision, but I do not want to disregard the importance of mentioning female genital mutilation in the same context. Some advocates of women's rights who emphasise FGM as a sign of gender based violence which springs from the patriarchal oppression of women, tend to be reluctant to allow any comparison between male and female genital mutilation and may disagree with my comparisons. $^{8}$ In this article, however, parallels between FGM and MGM are drawn only in respect of the implications of performing any potentially harmful non-therapeutic, nonconsensual procedure that in the end is, in one way or another, a social issue rather than a medical one. My purpose is not to diminish the ethical, social, and medical dangers involved in FGM, but to widen the scope of the discussion in this symposium. Focusing merely on male circumcision-and leaving it almost exclusively within a medical context-may make us forget that what we are discussing here is a 
historical tendency to look for rationalisations that allow us to practise genital mutilation in one form or another, across geographical, cultural, and religious boundaries.

I believe that examining the traditions of genital mutilation from the point of view of both sexes may reveal more clearly the irrationality involved in the justifications that are made for continuing the practice of mutilating human genitals. Thus, while there is a need to pay special attention to the elements of social and political oppression involved in FGM, it is also important to note that throughout time men, as well as women, have learned to accept that there are good reasons for the mutilations of human genitalia. Usually these reasons raise false hopes that undergoing the operation somehow improves people's lives-and the lives of their children-whether this be in the context of social status or of a medical condition, while the true reasons for the practice may lie elsewhere.

\section{AUTONOMY V CULTURAL RIGHTS - UNTANGLING THE DICHOTOMIES OF CULTURAL TRADITIONS}

When the justification of genital mutilation is discussed, the disputes are usually tangled around issues about the universality and relativity of our value systems, and can often centre on the conflict between the different rights that might be involved. In most cases, the debates for and against genital mutilation are set within the framework of collective cultural rights $v$ individual rights. The arguments against the practice of genital mutilation tend to appeal to the promotion of individual autonomy and universal human rights to various freedoms, while those who defend the practice draw support for their claims from demands to respect a person's particular cultural identity and/to protect the rights of minorities, (minority cultures) as for instance is argued by Veins. $^{3}$ (See also Mills ${ }^{910}$ and in connection with genital mutilation my own paper of 1999. ${ }^{11}$ )

In fact, Veins' argument further complicates this debate between individualism and collectivism by supporting male circumcision not only via an appeal to (religious) freedom and identity as such, but also by defending parents' rights to decide what is the best for their children. He supports MGM further by going on to defend our autonomy to decide what is our concept of the good life and wellbeing, while simultaneously refuting children's rights as not being real "rights" of autonomous and fully rational persons. This sets "autonomous", "adult" rights against children's rights. While children's rights tend to create a problem for the defence of autonomy and informed consent in general, Veins' view presents a rather contradictory rationalisation for male genital mutilation by championing parents' "cultural identity" against their children's physical integrity. There is always a danger in combining cultural and religious identity. The issue of religion and religious identity in the context of culture is in itself very complex: different cultures have different influences on the interpretations of religious norms, practices, and identities. Whether we talk about Islam, Christianity, Hinduism or any other world religion, each is followed very differently, depending on the original culture and the historical changes that have affected it: Islam and Christianity-for example, are practised very differently in Saudi Arabia, in Uganda, and in the UK.

On the other hand, Veins' argument provides a good example of how the dichotomy between individualism and collectivism presents a rather black and white picture of the cultural history of our world: individualism is tied inseparably to universalism and the universal promotion of human rights, while collectivist lifestyles are related directly to relativism, which allows social suppression. This polarisation of the positions simply overlooks the fact that individualistic values and lifestyles can also fall into relativist reasoning that rejects any interference with individuals' "autonomous" choices. This position clearly disregards the fact that most of our choices are made in a social context and may often be influenced by social pressures, or even by some refined forms of social coercion.

Also, an individualist culture, in the name of tolerance and freedom, may justify extremely violent and irrational practices, and "autonomous" parents can ask for their children to be physically mutilated in the name of their preferred collective identity. Collectivist value systems and cultural traditions, for their part, rely on a universal demand for the protection of religious and/or cultural rights and identities. ${ }^{12} 13$

Reconsidering descriptive and prescriptive senses of value systems can help us overcome normative cultural dichotomies and to avoid culturally biased discussions about genital mutilation and other harmful practices. In order to curb injurious practices we need to acknowledge that what makes some of these harmful customs so persistent is the tendency to see them as essential, integral, and identifying parts of particular cultures or belief systems. If, however, we recognised openly that the same or similar practices tend to appear universally - that is, the same or similar practices exist in one form or another in most parts of the world but with different rationalisations-we could see more easily the smokescreen that tends to blur moral argumentation around these practices. The best way to curtail any harmful and violent custom is to find a way to raise resistance to it within the communities themselves, by revealing the irrationality and dishonesty of the reasons put forward to maintain such customs as genital mutilation, and so their irrelevance to any cultural identity.

\section{MEN AND CIRCUMCISION IN THE "WILD" WEST}

Arguing about conflicting rights and cultural identities may lead us astray, if we do not invalidate some of the central fallacies that persist as part of the rationalisation process of genital mutilation. Firstly, if we are to have a serious "moral debate" on the persistent existence of genital mutilation, we need to recognise the various rationalisations used to defend it throughout human history, not merely in any particular time or age. Secondly, we need to further evaluate these rationalisations to see how they are successfully shaped to fit their local traditions and social environments. In most cases, these rationalisations are full of inconsistencies and act as a mere smokescreen to cover up the actual social, political, or economic reasons that are behind the preservation of genital mutilation in any given cultural context. Thirdly, recognising the complexity of the cultural and ethical issues involved in the justification process of genital mutilation may help us to find new ways to get rid off the false reasons for the practice and better ways to combat this violent practice worldwide.

Since the practice of genital mutilation has existed in almost all known civilisations at some time or another in various forms, we cannot say genital mutilation is a tradition that is unique to a particular culture or religion as such; and therefore we cannot say that defending the practice means defending the right of that culture to exist and defending the rights of its members to maintain their cultural identities. Since genital mutilation has appeared in a number of cultures and is related to various belief systems, it is not important whether these cultures or belief systems themselves are (more) individualist or (more) collectivist in their value structure: what is important is to pay more attention to the differences in the types of rationalisation put forward to support them within different types of cultural frameworks. In most cases it appears that whether the practice withers away or remains an integral part of that culture's identity, 
depends on the strength of the rationalisations and the availability of education in that culture.

Since genital mutilation is not alien to individualist cultures, we can look at the medical rationalisation of male circumcision in the Western individualist tradition. Within Western medical history cutting off or extracting the male foreskin has been believed to cure insanity, masturbation, epilepsy, cancer of the penis, and even cancer of the cervix of the future wives of the circumcised boys as well as sexually transmitted diseases and particularly phimosis (either as a disease or as a cause of other diseases such as cancer). Even today the relation between male circumcision and HIV/AIDS is still extensively studied and debated, as the articles by Hutson, Short, and Viens show. ${ }^{123}$ In particular, the claim that male circumcision is able in fact to prevent HIV/AIDS, can have negative consequences, especially in parts of the world where medical hygiene is poor and/or relevant health education is not readily available.

The claim that being circumcised helps to prevent HIV/ AIDS may in fact lead to triple jeopardy in the fight against AIDS. Firstly, where there is a lack of medical facilities for the operation the knives and other utensils used for the procedure might actually fuel the spread of AIDS. This further complicates Viens's argument for religious freedom, because he also recommends that the operation be carried out in modern medical facilities with more advance pain management. If this requirement is set in a global context, a logical, but nevertheless contradictory, consequence would be, that (male or female) circumcision should be allowed in the name of religion only in those parts of the world were hygiene and advanced medical treatments and technology are readily available. From the point of view of religious freedom this is a rather restrictive requirement.

Secondly, the fact that people believe they are somehow protected against HIV by being circumcised may cause them to be somewhat careless or dismissive about the need for other protection, to have promiscuous sex, and in general to feel they are now immune to the virus. Thirdly, the fact that male circumcision is seen to be medically related to the prevention of HIV/AIDS may lead onto a slippery slope that ultimately leads to it being culturally required that FGM is practised for the same purpose. This would be even more counterproductive, since there is medical evidence that women are more vulnerable to the virus to start with. Whatever medical indication there might be that male circumcision actually prevents the spread of HIV/AIDS, the effect of this in stopping the spread of the virus would be undermined if, as a result, more women were infected because of unsafe, and maybe also forced, sex.

All this shows that while opinions about the diseases that male circumcision is to be used to prevent or to cure have changed throughout time, male circumcision as such has persistently maintained its place as a medically justifiable practice in Western countries, and is gaining further justification as the papers by Hutson, Short, and Viens show. In addition, male circumcision has also had a longstanding religious rationalisation in the Western cultural context within Judaism, Islam, and even Christianity, as explicated by Viens; it has medical rationalisation to the level of being almost routinely practised in the United States and in Australia, as discussed by Hutson and Short; and in most cases it has an individual justification which is based on alleged medical conditions, as noted by Short. The medicalisation of this operation in the West has given the practice a stronger "rational" justification in a modern society than even traditional and religious demands can provide. ${ }^{14} 151617$

Whether the rationalisations of genital mutilation are cultural, aesthetic, religious, hygienic, medical, or scientific, the truth behind the practice of genital mutilation might still be a very different story. Even a medical rationalisation may cover up other more hidden purposes. If we compare the persistent continuation of male circumcision in the United States with the same phenomenon in Europe we find rather interesting results. The studies by Fletcher, ${ }^{14}$ and Fleiss ${ }^{18}$ show how in the United States, where the routine circumcision of newborn males has been common until rather recently, because of the widespread diffusion of the scientific myths about its benefits, the medical data with counter results were deliberately ignored or misinterpreted in order to maintain the practice. For instance, the latest reports from European medical research on the issue were neglected in order to maintain the practice in the USA even when it was already rapidly disappearing in Europe, as also noted by Hutson. ${ }^{1}$ Behind the disguise of alleged medical benefits we can find more gruesome reasons for the maintenance of the practice. In a modern, American, market oriented society male circumcision became a form of commercial exploitation of children when physicians, in cooperation with transnational biotechnology corporations, looked for the sales of marketable and economically profitable products made from harvested human foreskins that could further be used in the pharmaceutical industry (Fletcher, ${ }^{14}$ pp 259-71), (Sorrells, ${ }^{15}$ pp $331-7) .{ }^{17}$

\section{MALE CIRCUMCISION IN AFRICA AND BEYOND}

The practice of genital mutilation plays a central role in social hierarchies and personal relationships (not only between the different genders, but also between men themselves and between women themselves). Whether the rationalisation for male circumcision is a religious, cultural, medical or hygienic one, those men who remain uncircumcised in the societies in which the practice is common, are made to feel somehow abnormal and/or not equal to those who have undergone the operation. Just to take a few local examples: in East Africa, for instance, men of the Masai tribe see uncircumcised men as adolescent, spineless, and timid cowards who do not have full male qualifications (whether we talk about the uncircumcised men of their own community, or those of other tribes or races). Within the Cameroonian Nso tribe the three main rationalisations for male circumcision have been firstly, the belief that circumcision prepares the penis, puts it in a state of readiness for coitus and procreation, secondly that it tests the courage and endurance of a boy at the threshold of adulthood, and thirdly, but rather in contradiction of the first claim, it is thought to tame and moderate the sexual instinct thereby helping a man to act more responsibly. ${ }^{19}$

The Tanzanian Chagga tribe, for its part, circumcises young boys in different age groups (thus the age for circumcision may vary from 4 to 18 ). In cases where the circumcision is postponed for a long time, for one reason or another, by the parents and relatives, many of the boys seek a way to go through the operation on their own, endurance of pain being a central element of the ritual. Before having the operation done to them they feel socially and physically immature. With the modern Chagga, many of whom are now Catholics by religion, the rationalisation for circumcision is nowadays hygienic rather than traditional. The Islamic Chagga, for their part, can appeal to the demands of their religion, for circumcision. In reality, however, the practice is clearly based on peer pressure and the community's social expectations. Uncircumcised men in many African communities are seen as undeveloped or "child like" and are thought to be inclined to poor sexual or reproductive performance.

Social pressures are also typical in the societies in which the rationalisation is more purely based on religious demands. It may seem inconsistent to require genital mutilation on a religious basis since this is perfecting the work of God by cutting off, modifying or redesigning any part 
of a human body which has been created by God. The human ability to find the needed false reasons, however, is boundless; in the case of genital mutilation the attempt to reduce sexual pleasure and to maintain chastity is seen not only as an improvement of God's work, but also as showing obedience to whatever is believed and interpreted to be God's will in any given culture. In traditional Judaism, for instance, male circumcision is a means to moderate the sexual pleasure of men and their attraction to women. Similar views, to do with reducing the sexual pleasure rather than fully suppressing it, have been presented in Islam. In Islam the argument linking pleasure to circumcision, however, is used more frequently in the case of female genital mutilation. In most religions (as for Jews and Muslims) circumcision is also a mark that distinguishes the believer from the non-believer. The fact that circumcision has, throughout history, been practised also within traditional belief systems-for example, by Australian Aborigines, the Mayas of Borneo, various Native American tribes, the ancient Aztecs and Mayas, etcis not taken as undermining the claim that this practice is seen as a sign that distinguishes a believer from a nonbeliever in such world religions as Islam or Judaism. ${ }^{4} 50-23$ In general then when the justification of genital mutilation is based on traditional or religious grounds, whether in Arab, Eastern, Western or Southern cultures, the emphasis has been on God's will as well as the purity of body and mind.

All in all, the inconsistencies between sexual performance and religious identity in relation to genital mutilation do not seem to reduce the power of the false reasons put forward to support the practice. In some cultures circumcision is justified as a means to control men's and women's sexual desires, while in others it is used for precisely the opposite purpose, that is to prove the sexual virility and endurance of men. In yet other cultures it is used to enforce traditional and natural cultural identity and social order, and in others it is used to mark religious affiliation and God's will.

\section{FEMALE GENITAL MUTILATION AND GENDER EQUALITY}

Female genital mutilation, for its part, is usually seen as part of traditional and collectivist cultures with patriarchal social structures. It is not, however, fully alien to the more individualist Western cultural tradition. Female genital mutilation used to be practised in Western civilisations as a cure for various medical conditions while the actual social reasons for its maintenance may have lain elsewhere in Western history. Clitoridectomy was, for instance, used both in Europe and in America for hygienic reasons, as a medical cure for masturbation, and for mental disorders such as hysteria. Since in the West both male and female circumcision were practised by qualified doctors for allegedly legitimate medical indications, they were not considered to be the same brutal and intervening mutilations of the human body as they were seen to be elsewhere in so called "more primitive" societies. This shows that science can be a double edged sword that readily lends itself as an alibi for strongly held preferences and cultural biases. In particular, the medicalised nature of the Western culture itself can give legitimisation to even violent and unnecessary physical interventions on the human body in the name of science, progress, normality, and health while the actual reasons for such interventions may remain hidden. ${ }^{11}$

Today, female genital mutilation, now called traditional circumcision, no longer exists openly in the Western cultural mainstream, but it persists in the developing world. With the relatively recent emphasis on pluralist values, tolerance, and respect for personal autonomy, however, practices of genital mutilations have recurred in the West. Body piercing and other rather extremist forms of sexual (pleasure seeking) subcultural practices have introduced new, less openly condemned, forms of genital mutilation. These contemporary forms of genital mutilation are taken to be more acceptable since they are thought to have come about as a result of one's autonomous choice and free will. Thus, the main ethical battle against genital mutilation in Western culture still focuses more on preventing the traditional forms of FGM, which also is practised (though mostly in secret) within various immigrant communities in multicultural Western societies. Here again, we can note that the culture itself introduces the same practice (in different forms) over and over again, succeeding always in finding a culturally fitting justification for it, while being simultaneously more than ready to reject the same or similar custom in other cultures. $^{8} 24$

While, however, many traditional communities where FGM is practised remain clearly more patriarchal and use female genital mutilation to control women's sexual behaviour, economic factors should not be ignored. Those performing the operation earn a good income out of it and thus, the practice provides livelihoods for many. Also, circumcised girls guarantee better bride prices and higher social status for their families. This may help us to understand why not only men, but also women themselves, while victims of the practice of FGM, are often its strongest proponents. It is true that the more traditional types of female genital mutilation clearly have more devastating medical consequences for their victims, particularly in poor environments and in unhygienic conditions. In addition, they are usually performed on vulnerable and defenceless children. Thus, evidently there is an urgent need to find a ways to curtail the practice. Additionally, as noted, female genital mutilation tends to persist in societies that have a more traditional, a more patriarchal social structure, thus its maintenance is more directly related to the low social status of women. Female genital mutilation in traditional environments is said to be harder to combat, since its persistent maintenance is usually based on women's lack of education and decision making power in their communities. Thus, the abolition of FGM is not merely in hands of its direct victims. It is also in the hands of the society as a whole, and particularly in the hands of those in social and political or religious power. Power relations between the sexes, however, are difficult to change and thus, the practice persists and is justified in a manner that makes women themselves adopt it as a part of their cultural identity and of their social pride through history. In Africa, for instance, the history of female genital mutilation dates back to 4000 years BC. Even today in Africa FGM is still practised in at least 27 countries and every year two million girls at least are exposed to sexual mutilation. These mutilations constitute one aspect of a series of traditional practices harmful to women's health and welfare-that is, forced marriages and early pregnancies, force feeding, tattooing, scarification, and nutritional taboos. Also, although some people consider the practice of FGM to be recommended by Islam, Christianity, and traditional religions, there are non-believers who practise this as well. These practices are also found in Egypt as well as in the majority of Arab Muslim countries of the Middle and Near East as well as in Islamic societies in the Far East. ${ }^{6} 825$ Finally, it should not be overlooked that women are also involved in the maintenance of male genital mutilation. In the case of MGM, setting aside religious or traditional rationalisations or social pressures from the community, women (those who themselves have not undergone any genital mutilation, as in the US-for example) may prefer circumcised men as sexual partners, either because their performance in sexual intercourse lasts longer or because they consider a circumcised 
penis to be more hygienic and/or more aesthetic than an uncircumcised one.

\section{CONCLUSION}

Human sexuality and the attempts to control it, particularly to reduce or add sexual pleasure, have been, in one way or another, a part of all known cultures and civilisations. While sometimes this fact is acknowledged openly as the main purpose for genital mutilation, in most cases other rationalisations are put forward for the practice. These false reasons have varied from religious and cultural demands to a number of medical "explanations", depending on the wider cultural tradition within which the practice has appeared. These different rationalisations for the maintenance of the practices in various cultures show that no matter what the cultural differences are in beliefs and lifestyles, genital mutilation is a universal sign of human civilisation-or maybe the lack of it. All societies have found the arguments that best fit their local cultural traditions and environments in order to introduce or maintain genital mutilation in its various forms. In the Western, rather individualist tradition, these rationalisations are based on benefit to the individual and/or autonomy; in the Southern and Eastern cultures their support is drawn more directly from social values and ties, or from the need to protect one's unique cultural identity against Western cultural imperialism. Thus, in this regard one cultural tradition cannot be said to be better than another. Rather, with further education and knowledge the cultural smokescreen around the real reasons for the maintenance of the practice can be overcome in all societies no matter what their cultural background.

\section{REFERENCES}

1 Hutson JM. Circumcision: a surgeon's perspective. J Med Ethics 2004;30:238-40.

2 Short R. Male circumcision: a scientific perspective. J Med Ethics 2004;30:241.

3 Viens A. Value judgment, harm, and religious liberty. J Med Ethics 2004;30:241-7

4 Aldeeb Abu-Salieh SA. Muslims' genitalia in the hands of the clergy: religious arguments about male and female circumcision. In: Denniston GC, Mansfield Hodges F, Fayre Milos M, eds. Male and female circumcision: medical, legal, and ethical considerations in pediatric practice. New York: Kluwer Academic/ Plenum, 1999:131-71

5 Bigelow JD. Evangelical Christianity and its relation to infant male circumcision. In: Denniston GC, Mansfield Hodges F, Fayre Milos M, eds. Male and female circumcision: medical, legal, and ethical considerations in pediatric practice. New York: Kluwer Academic/Plenum, 1999:173-7.

6 Anon. Female genital mutilation. Echo. Bilingual Quarterly of the Association of African Women for Research and Development. 2001 Oct 6:2.
7 Anon. Female genital mutilation. WHO Chronicle 1986:40:31-6.

8 Toubia N. Female genital mutilation. In: Peters J, Wolper A, eds. Women's rights, human rights. London: Routledge, 1995:2-7.

9 Mill JS. On liberty. New York: Prometheus Books, 1986.

10 Mill JS. Utilitarianism. New York: Prometheus Books, 1997.

11 Hellsten SK. Pluralism in multicultural liberal democracy and the justification of female circumcision. J Appl Philos 1999; 16:69-83.

12 Hellsten SK. Multicultural issues in maternal fetal medicine. In: Dickenson DL, ed. Ethical issues in maternal fetal medicine. Cambridge: Cambridge University Press, 2002:39-60.

13 Kukathas C. Are there any cultural rights? Polit Theory 1992;20:105-39.

14 Fletcher CR. Circumcision in America in 1998: attitudes, beliefs, and charges of American physicians. In: Denniston GC, Mansfield Hodges F, Fayre Milos $M$, eds. Male and female circumcision: medical, legal, and ethical considerations in pediatric practice. New York: Kluwer Academic/Plenum, 1999:159-271 at 259-71.

15 Sorrells ML. The history of circumcision in the United States: a physician's perspective. In: Denniston GC, Mansfield Hodges F, Fayre Milos M, eds. Male and female circumcision: medical, legal, and ethical considerations in pediatric practice. New York: Kluwer Academic/Plenum, 1999:331-7.

16 Whitfield HN. Publication on circumcision in the medical literature: the role of an editor. In: Denniston GC, Mansfield Hodges F, Fayre Milos M, eds. Male and female circumcision: medical, legal, and ethical considerations in pediatric practice. New York: Kluwer Academic/Plenum, 1999:403-7 at 403-6.

17 Denniston GC. Tyranny of the victims: an analysis of circumcision advocacy. In: Denniston GC, Mansfield Hodges F, Fayre Milos M, eds. Male and female circumcision: medical, legal, and ethical considerations in pediatric practice. New York: Kluwer Academic/Plenum, 1999:221-239.

18 Fleiss PM. An analysis of bias regarding circumcision in American medical literature. In: Denniston GC, Mansfield Hodges F, Fayre Milos M, eds. Male and female circumcision: medical, legal, and ethical considerations in pediatric practice. New York: Kluwer Academic/Plenum, 1999:379-401.

19 Tangwa GB. Circumcision: an African point of view. In: Denniston GC, Mansfield Hodges F, Fayre Milos M, eds. Male and female circumcision: medical, legal, and ethical considerations in pediatric practice. New York: Kluwer Academic/Plenum, 1999:183-93 at 186

20 Baker JP. Unifying language: religious and cultural considerations. In: Denniston GC, Mansfield Hodges F, Fayre Milos M, eds. Male and female circumcision: medical, legal, and ethical considerations in pediatric practice. New York: Kluwer Academic/Plenum, 1999:195-9.

21 Goodman J. Jewish perspective on circumcision. In: Denniston GC, Mansfield Hodges F, Fayre Milos M, eds. Male and female circumcision: medical, legal, and ethical considerations in pediatric practice. New York: Kluwer Academic/ Plenum, 1999:179-81.

22 Trachtenberg M. Psychoanalysis of circumcision. In: Denniston GC, Mansfield Hodges F, Fayre Milos M, eds. Male and female circumcision: medical, legal, and ethical considerations in pediatric practice. New York: Kluwer Academic/ Plenum, 1999:209-13.

23 Toubia N. Evolutionary cultural ethics and circumcision of children. In: Male and Female Circumcision: Medical, Legal, and Ethical Considerations in Pediatric Practice, In: Denniston GC, Mansfield Hodges F, Fayre Milos M, eds. Male and female circumcision: medical, legal, and ethical considerations in pediatric practice. New York: Kluwer Academic/Plenum, 1999:1-7.

24 Benhabib S. Cultural complexity, moral interdependence, and the global dialogical community. In: Nussbaum M, ed. Women, culture and development. Oxford: Clarendon Press, 1995:235-55.

25 UNICEF research report: The girl child in Tanzania. Dar es Salaam: UNICEF 1995. 